\title{
Nichos,
}

\section{cámaras y ceremonias en el templete Tulán-54 (Circumpuna de Atacama, Chile}

Niches, chambres et cérémonies dans le temple Tulán-54 (Circumpuna de

Atacama, Chili)

Niches, chambers and ceremonies at Tulán-54 temple (Atacama Circumpuna, Chile)

Lautaro Núñez, Isabel Cartajena, Patricio López M., Carlos Carrasco, Marta Valenzuela y Álvaro Bravo

\section{OpenEdition}

\section{Journals}

Edición electrónica

URL: http://journals.openedition.org/bifea/10458

DOI: 10.4000/bifea.10458

ISSN: 2076-5827

\section{Editor}

Institut Français d'Études Andines

\section{Edición impresa}

Fecha de publicación: 1 abril 2019

Paginación: 57-81

ISSN: 0303-7495

\section{Referencia electrónica}

Lautaro Núñez, Isabel Cartajena, Patricio López M., Carlos Carrasco, Marta Valenzuela y Álvaro Bravo, "Nichos,cámaras y ceremonias en el templete Tulán-54 (Circumpuna de Atacama, Chile) », Bulletin de I'Institut français d'études andines [En línea], 48 (1) | 2019, Publicado el 08 abril 2019, consultado el 05 noviembre 2020. URL : http://journals.openedition.org/bifea/10458; DOI : https://doi.org/10.4000/ bifea.10458

\section{(c) (i) $\odot$}

Les contenus du Bulletin de l'Institut français d'études andines sont mis à disposition selon les termes de la licence Creative Commons Attribution - Pas d'Utilisation Commerciale - Pas de Modification 4.0 International. 


\title{
Nichos, cámaras y ceremonias en el templete Tulán-54 (Circumpuna de Atacama, Chile)
}

\author{
Lautaro Núñez*, Isabel Cartajena**, Patricio López M. ${ }^{* *}$, \\ Carlos Carrasco ${ }^{* * * *}$, Marta Valenzuela ${ }^{* * * * *}$ y Álvaro Bravo ${ }^{* * * * *}$
}

\begin{abstract}
Resumen
Se describen y analizan los contenidos de los nichos-cámaras incluidos en el muro perimetral del templete Formativo Temprano Tulán-54, ubicado al sureste de la Circumpuna atacameña. La identificación, en su gran mayoría de restos óseos de animales, desechos líticos, mineral de cobre, fragmentos cerámicos, la inhumación de un adulto y la ofrenda de un metate, además de una vasija completa del patrón Tilocalar-Los Morros, fechado en 2640 AP (2765 a 2715 cal. AP), indica una coherente relación con los eventos fundacionales del templete. El registro de un infante ubicado en el interior de una cámara sellada vinculada con la arquitectura ceremonial fue fechado en 2600 AP (2750 a 2700 / 2630 a 2620 / 2560 a 2540 cal. AP), en sincronía con el uso de los nichos. Se discute en general la naturaleza y temporalidad de los contextos asociados y se concluye que las evidencias presentadas en los nichos-cámaras estuvieron vigentes durante las tempranas prácticas performáticas del templete.
\end{abstract}

Palabras clave: salar de Atacama, Fase Tilocalar, templete, nichos, ofrendas

* Instituto de Arqueología y Antropología, San Pedro de Atacama, Universidad Católica del Norte, Calle Gustavo Le Paige n. 380, San Pedro de Atacama, Chile. E-mail: lautaro.nunez@hotmail. com

** $\quad$ Facultad de Ciencias Sociales, Departamento de Antropología, Universidad de Chile, Ignacio Carrera Pinto 1045, Nuñoa, Santiago, Chile. E-mail: isabel.cartajena@uchile.cl

*** Investigador independiente. E-mail: patriciolopezmend@gmail.com

**** Colegio de Arqueólogos A.G., Santiago, Chile. E-mail: carrcag@gmail.com

***** Investigadora Asociada al Proyecto Fondecyt 1130917. E-mail:mmva@live.cl

****** Investigador Asociado al Proyecto Fondecyt 1130917. E-mail: alvaro.bracast@gmail.com 


\title{
Niches, chambres et cérémonies dans le temple Tulán-54 (Circumpuna de Atacama, Chili)
}

\section{Résumé}

Dans cet article, est décrit et analysé le contenu des niches-chambres insérées dans le mur d'enceinte du temple Formatif Ancien Tulán-54, situé au sud-est de la Circumpuna atacameña, . L'identification de restes d'ossements d'animaux, de débris d'origine lithique, de minerai de cuivre, de fragments de céramique, ainsi que l'inhumation d'un adulte et l'offrande d'un metate, en plus d'un vase complet du type Tilocalar-Los Morros, daté de 2640 AA (2765 à 2715 cal. AA), indiquent une relation cohérente avec les événements fondateurs du temple. La sépulture d'un enfant, trouvée à l'intérieur d'une chambre scellée liée à l'architecture cérémoniale, fut datée de 2600 AA (2750 à 2700 / 2630 à 2620 / 2560 à 2540 cal. AA), période qui coïncide avec l'utilisation des niches. Nous discutons de la nature et de la temporalité des contextes associés et nous concluons que les témoins contenus dans les nicheschambres faisaient partie des premières pratiques performatives du temple.

Mots-clés : Salar d'Atacama, Phase Tilocalar, temple, niches, offrandes

\section{Niches, chambers and ceremonies at Tulán-54 temple (Atacama Circumpuna, Chile)}

\begin{abstract}
In this article, the contents of the niche-chambers situated within the perimeter wall of the Early Formative temple Tulán-54, located in the south-east of the Circumpuna Atacameña, are described and analyzed. The identification of animal bones, remains of lithic debris, of copper ore and ceramic fragments, as well as the burial of an adult, a metate offering and an entire Tilocalar-Los Morros type vessel, dated to $2640 \mathrm{BP}$ (2765 to $2715 \mathrm{cal}$ BP), indicate a relationship with the temple founding events. An infant burial found inside a sealed chamber of the ceremonial architecture was dated to 2600 BP (2750 to 2700 / 2630 to 2620 / 2560 to 2540 cal. BP), a period synchronous with the use of the niches. The nature and dating of the associated contexts are discussed in general and we reach the conclusion that the evidence found in the niches-chambers was part of the early performance practices of the temple.
\end{abstract}

Keywords: Salar de Atacama, Tilocalar Phase, Small Temple, Niches, Offerings

\section{INTRODUCCIÓN}

En distintas regiones del mundo, y en particular en el espacio andino, la arquitectura ceremonial ha expuesto de forma reiterada ciertas formas distintivas como el empotramiento de pilares o jambas verticales que sostienen un dintel horizontal, desde escalas megalíticas hasta más discretas (Canziani, 2009). Estos componentes han motivado diversas interpretaciones sobre actos rituales bajo un umbral, siendo más comunes aquellos aperturados o intruidos en muros con el fondo sellado, presentes en templos a través de una amplia escala espacial y temporal: Arcaico, Formativo, Intermedio Tardío e Inca (Mujica, 1985; Onuki, 1993; Bueno, 1998; Eeckhout, 1998; Shady, 2001; Tantaleán, 2006; Canziani, 2009; Alva Meneses, 2012; entre otros). 
Se acepta la posibilidad que algunos casos en los Andes centrales serían parte de la transición Arcaico-Formativo (Bonnier, 1987). Sin embargo, son escasos los análisis de sus contenidos $u$ ofrendas en contextos formativos tempranos, como ha ocurrido en el sitio Pukara (Mujica, 1985; Canziani, 2009) o en el «Templo de los Nichitos» en Kotosh, donde se han colocado huesos de cuy (Cavia sp.) y de camélidos con golpes de fuego, es decir evidencias de exposición al fuego (Onuki, 1993; 1999; Canziani, 2009). Se ha identificado la presencia de nichos tanto en estructuras arcaicas como formativas en el centro sur andino y en la Circumpuna de Atacama con contextos, escalas y arquitectura diferenciadas (Núñez et al., 2009a; Núñez \& Santoro, 2011). Es el caso de los quince nichos del Formativo Temprano que integraron el diseño arquitectónico del templete central de Tulán (figs. 1, 2), conectados a cámaras o bóvedas por el exterior del muro perimetral, incluidos dos registros en una pequeña estructura con similares atributos junto al templete (Núñez et al., 2017a).

De acuerdo con estudios previos, tanto el templete Tulán como las estructuras y depósitos de su entorno han sido considerados partes de un centro ceremonial convergente que incluyó uno o más templetes (investigación en curso). Se destacan diversos componentes: inhumaciones de infantes con ofrendas jerárquicas, fogones estructurados, bloques con arte rupestre — destacándose grabados con cabezas de camélidos y cortes longitudinales - inhumaciones de adultos bajo emplantillados de rocas y un cementerio anexo. Todo fue cubierto deliberadamente con materiales descartados residuales in situ o trasladados desde áreas de actividades externas, conformando un túmulo extendido. No obstante, restaba identificar el rol de los portales o nichos y las respectivas cámaras adosadas (Núñez et al., 2017a).
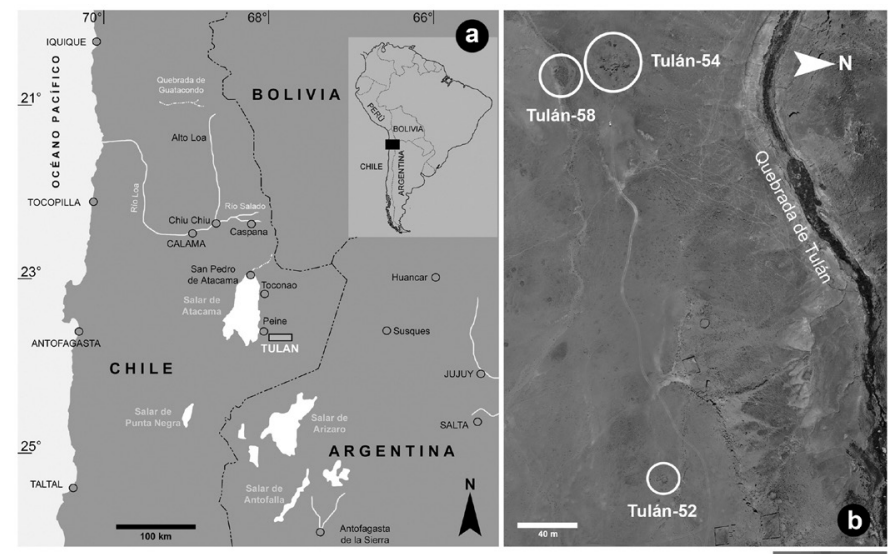

$$
\begin{aligned}
& \text { Simbología } \\
& \text { S Salar de Atacama } \\
& \text { Oasis de Tilomonte } \\
& \ddots \text { Quebrada de Tulán }
\end{aligned}
$$

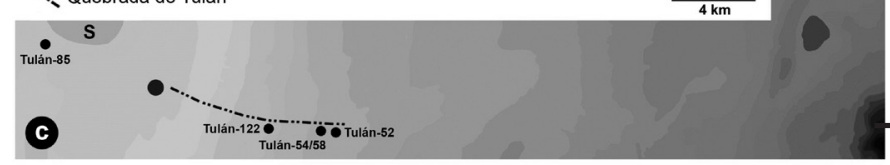

Figura 1 - (a) Ubicación del área de estudio. (b) Ortofoto con la ubicación y la relación espacial de los sitios Tulán-54, 58 y 52 (fotografía tomada por Latorre Geomensura). (c) Mapa con la ubicación de los sitios mencionados en el texto

(c) Patricio López M. y Latorre Geomensura 


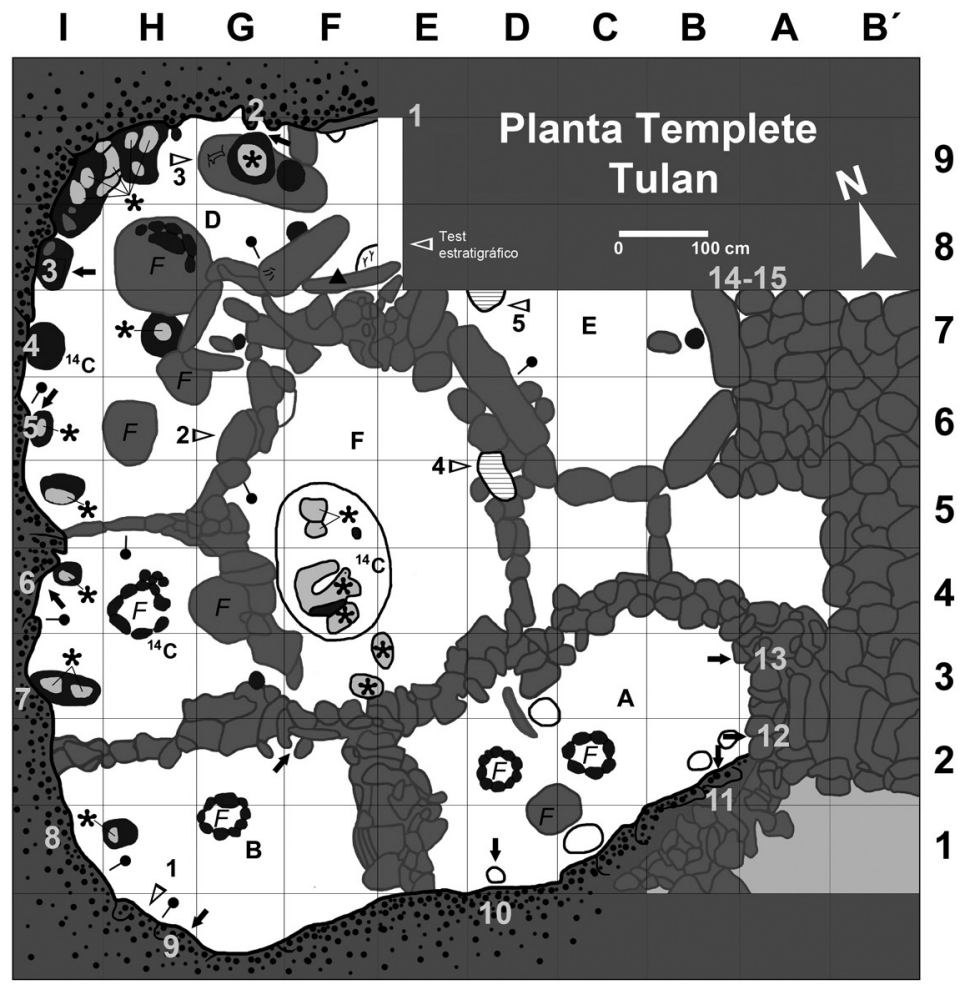

Simbología

A, B, C, D, E y F: Estructuras

$F$ : Fogones estructurados y abiertos

$\triangleright$ : Petroglifos en estructuras Nos 1,2 y 3

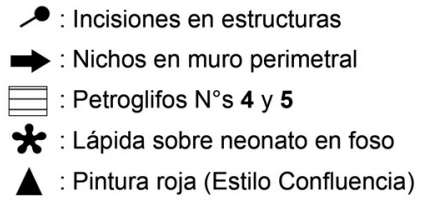

- Incisiones en estructuras

: Petroglifos $\mathrm{N}^{\circ} \mathrm{s} \mathbf{4}$ y $\mathbf{5}$

$\Delta$ : Pintura roja (Estilo Confluencia)
9

8

7

6

5

4

3

2

1

Figura 2 - Ubicación de los nichos (números) y otros indicadores en el plano del templete Tulán

(C) Dibujo tomado y modificado de Núñez et al. (2017a: 7)

Los nichos de Tulán están constituidos por portales con jambas y dinteles no convencionales, en cuanto «perforan» el muro perimetral a diferencia de aquellos más comunes con el fondo sellado (fig. 3a). Las cámaras se han techado con grandes lajas horizontales complementadas con bloques acumulados, adosados al exterior del muro perimetral e incorporados a la arquitectura del templete (fig. 3b ). Los nichos están presentes inicialmente en estructuras arcaicas tardías, y se han hecho más numerosos con las primeras comunidades pastoralistas formativas localizadas en quebrada Tulán al este del salar de Atacama. Sin embargo, no se han identificado hasta ahora templetes con nichos en asentamientos vinculados con la fase Tilocalar localizados en Puripica (Pu-31 B) y Gatchi, al NE de San Pedro de Atacama (Núñez, 2005; Adán \& Urbina, 2007; Agüero \& Uribe, 2011). 

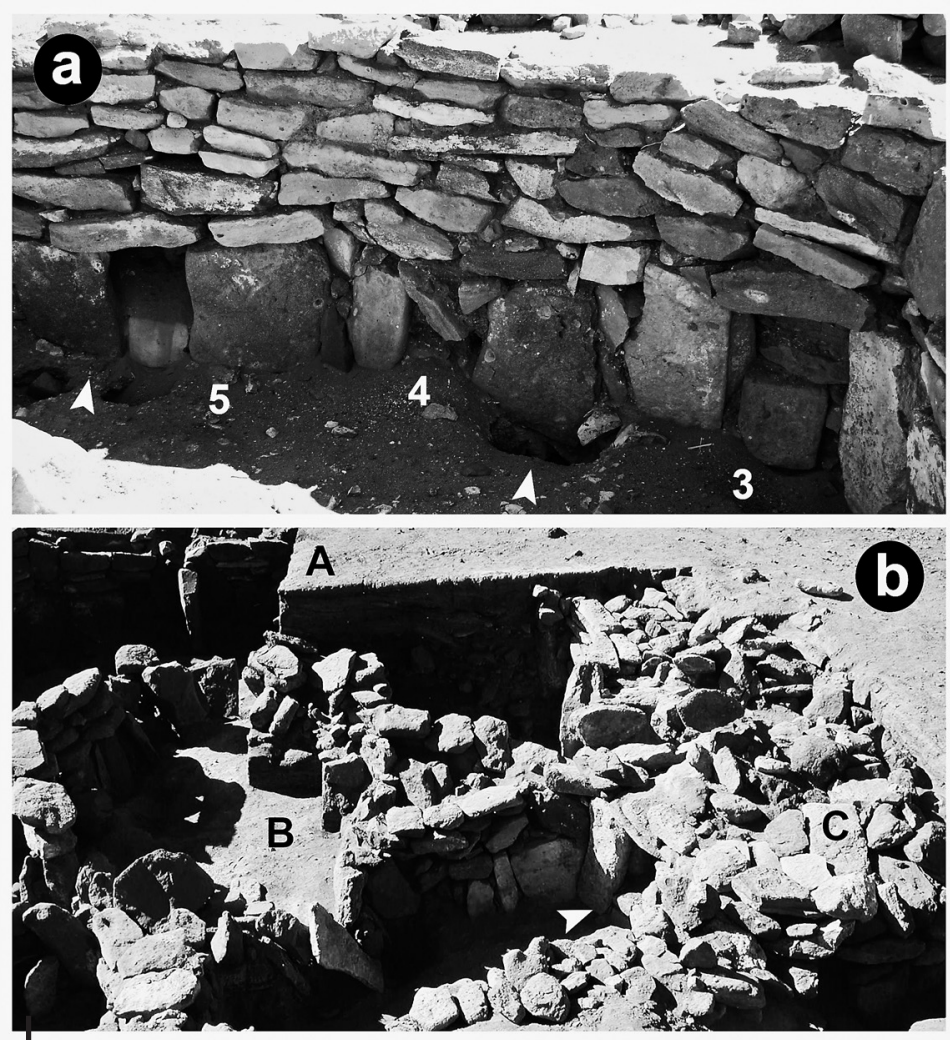

Figura 3 - (a) Detalle del muro perimetral del templete Tulán con los nichos $n .^{\circ} 3,4$ y 5 sobre el piso, que conectan con las cámaras externas Las flechas señalan los fosos de inhumación de los infantes

(b) Detalle del sector este del templete Tulán. A. Bloque-testigo del depósito estratigráfico. B. Estructura central. C. Cámaras correspondientes a los nichos 12, 13, 14 y 15, y acumulamientos de rocas de soporte del muro perimetral

La flecha indica el nicho . $^{\circ} 13$

(C) Lautaro Núñez A.

Para examinar la conexión entre los nichos y las cámaras se retiraron los sedimentos superficiales sobre los «techos» en ciertos sectores ubicados frente a los nichos; a continuación se procedió a excavar desde el interior del templete, por la apertura de los nichos seleccionados, para evaluar la existencia de posibles ofrendas entre ambos. Para contextualizar el contenido de estas cámaras se excavó una de factura menor que estuviera sellada y vinculada con una estructura ceremonial complementaria al templete, con el fin de extrapolar su función con aquellas mayores no excavadas (figs. 4, 5). 


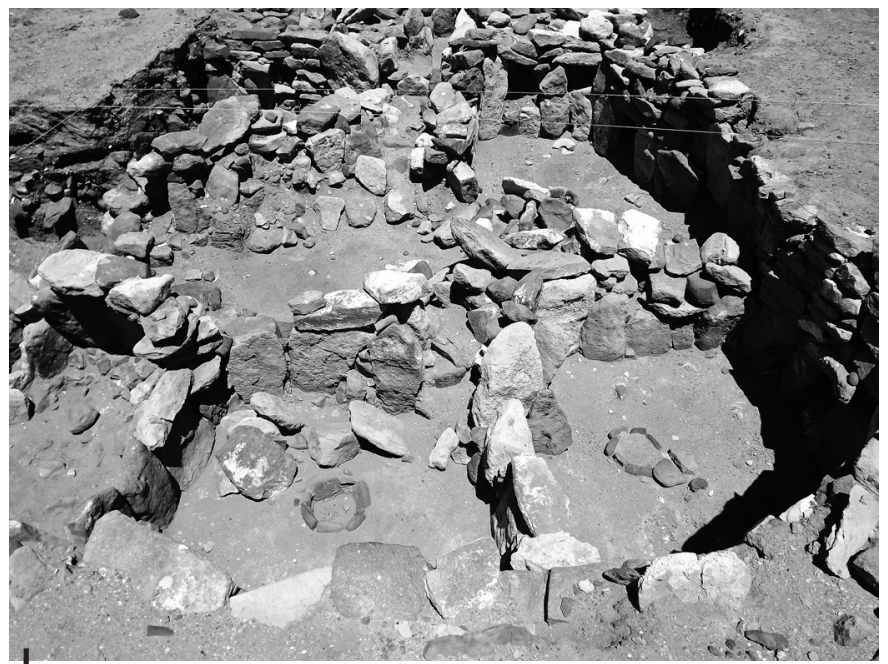

Figura 4 - Panorama del templete Tulán después del decapado, correspondiente al Periodo Formativo Temprano, ubicado al sureste del salar de Atacama

(C) Lautaro Núñez A.

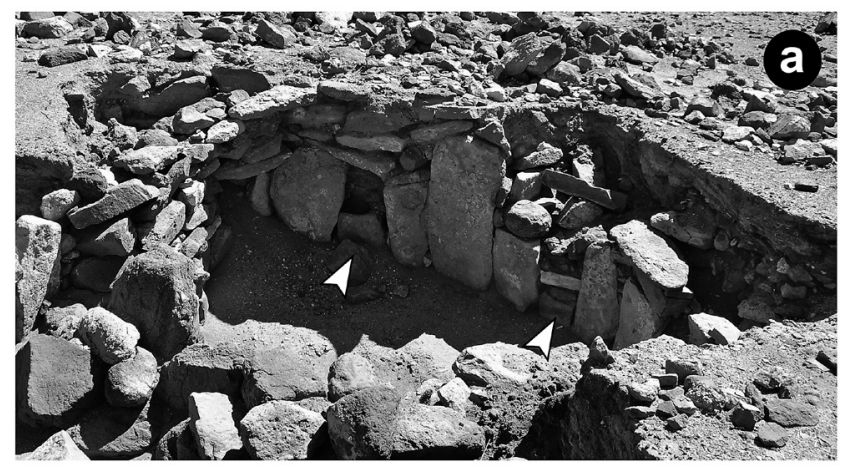

Figura 5 (a) Estructura periférica ubicada junto al templete Tulán con fines homólogos

Las flechas señalan dos nichos interiores (nichos sin número)

(b) Interior del templete Tulán

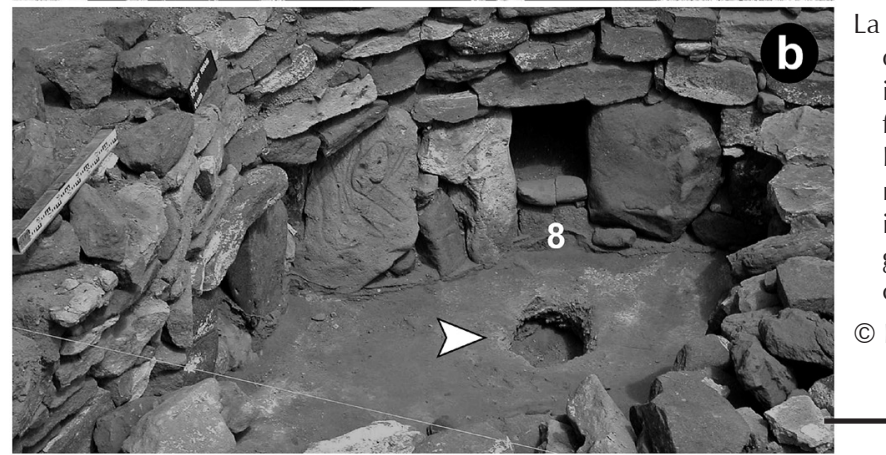

La flecha indica el foso donde se registró la inhumación de un infante frente al nicho n. ${ }^{\circ} 8$. En su base conserva un metate de molienda. A la izquierda se encuentra un grabado con cabeza de camélido

(C) Lautaro Núñez A. 


\section{LA SECUENCIA ARCAICA-FORMATIVA DE LOS NICHOS Y CÁMARAS}

La presencia de nichos se ha distinguido inicialmente durante la fase arcaica tardía Puripica-Tulán al sureste de la Circumpuna de Atacama, más precisamente en la arquitectura ceremonial arcaica correspondiente al sitio Tulán-52, datado entre los 3450 y 2250 a. C. (fase Puripica-Tulán: 5290-4840 a 4430-4090 cal. AP), situado a unos $800 \mathrm{~m}$ del templete Formativo Temprano ubicado en Tulán-54 (fig. 6a). Se han decapado dos estructuras subcirculares estrechas con nichos construidos con lajas verticales. El examen de la estructura mayor expuso descartes y prácticas rituales, plasmados en un monolito abatido en línea con el muro, un foso de ofrendas vacío a nivel de piso y un nicho compuesto por dos jambas que sostienen un dintel apegado al muro y que se comunica con una pequeña cámara abatida (De Souza et al., 2010). Bajo el dintel se encontró un bloque mueble con grabados longitudinales, similar a otros distribuidos en varios sectores del sitio, iguales a los recurrentes durante la siguiente fase Tilocalar. De este modo, los nichos, aun con escasa frecuencia, se asocian a actividades ceremoniales en recintos estrechos de uso no doméstico, en contextos de cazadores-recolectores asociados al inicio de la domesticación de camélidos (Cartajena et al., 2007).
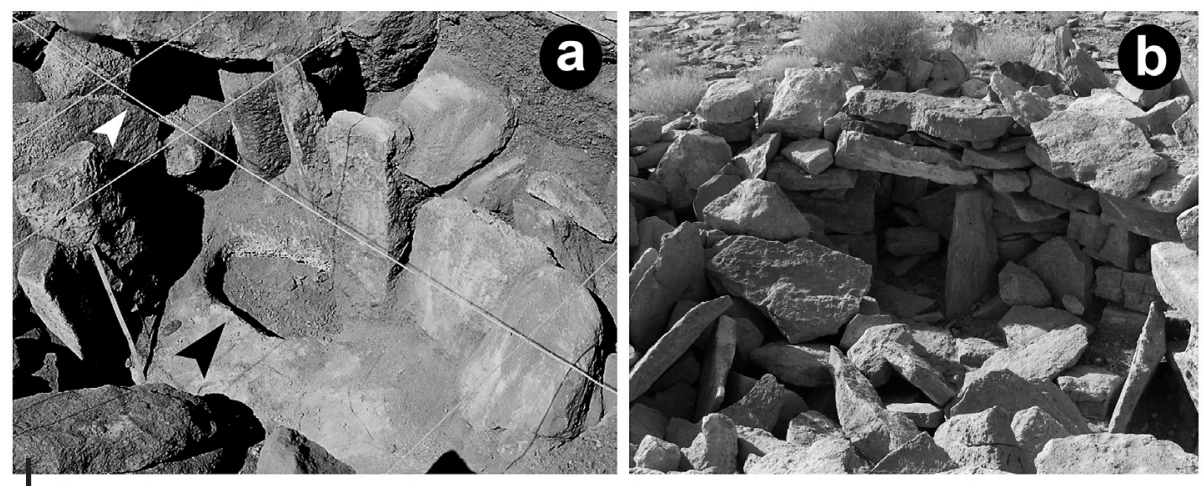

Figura 6 - (a) Estructura decapada de uso ceremonial correspondiente al sitio Tulán-52, aledaño al templete Tulán-54, perteneciente al periodo Arcaico Tardío

La flecha superior señala un nicho inicial con un bloque grabado con cortes lineales bajo el dintel. La flecha inferior marca un foso vacío.

(b) Estructura aislada con nicho, ubicada en el asentamiento Tulán-122 y correspondiente al periodo Formativo Temprano durante los comienzos de su aplicación posarcaica

(c) Lautaro Núñez A.

Se han identificado más nichos en el asentamiento Tulán-122, correspondiente a la fase Tilocalar, ubicado a unos 3,5 km aguas abajo de Tulán-54, junto a recintos asociados a restos domésticos, donde se han documentado 153 estructuras, algunas aglomeradas y la mayoría dispersas. Presentan atributos formativos tempranos, tanto en su arquitectura como en la materialidad cultural, datados en 
2740 AP (3230 a 2960 cal. AP / 1280 a 1010 cal. a. C.). Se trata de ocupaciones pastorales móviles, sin depósitos estratigráficos potentes, que habrían ocupado este espacio de un modo temporal e intermitente (Núñez et al., 2006). Por otra parte, el análisis cerámico indica que los contenedores adquirieron un carácter expeditivo (Kalazich \& Ugarte, 2008). Se destacan nichos alrededor del recinto y en casos aislados hay un nicho en cada estructura (fig. 6b), sugiriendo que aún no se habían integrado completamente en estructuras de mayor complejidad como en el templete de Tulán-54.

Es posible que en Tulán-122 se construyeran nichos arcaicos, por cuanto junto a las estructuras formativas se ha localizado un sector con recintos y materialidad arcaica tardía del patrón Tulán-52 (p.e. morteros cónicos), en un caso datado en 4120 AP (4820 a 4520 cal. AP / 2870 a 2570 cal. a. C.) (Gutiérrez, 2006; Núñez et al., 2006; Carrasco, 2007). Sin embargo, la distancia cronológica de 1600 años es significativa (Núñez et al., 2006). Desde otra perspectiva temporal, la diferencia es mínima si constrastamos la fecha del orden de 1280 a 1010 a. C. que tenemos para Tulán-122 con su contraparte del templete de Tulán-54, datado entre 910 y 560 a. C. (ver fig. 7a), siendo posible su transferencia en un marco de una mayor intensidad ceremonial en el templete.

\section{LAS CARACTERÍSTICAS DE NICHOS Y CÁMARAS DEL TEMPLETE}

El proceso constructivo del templete de Tulán-54 implicó acciones combinadas, iniciadas con el levantamiento del muro perimetral que alternó entre machones verticales o dinteles y la apertura de los nichos con las jambas horizontales presionadas por las hiladas superiores. Terminado el muro y los quince nichos que lo «perforan», se procedió a levantar en la parte exterior las cámaras apegadas a la apertura de los nichos, disponiendo inhumaciones en su interior, expresiones de arte rupestres (ver figs. 7b, 7c) y ofrendas. Luego se rellenaron las cámaras hasta sellarlas con lajas horizontales $y$, paralelamente, se apilaron bloques sobre y entre las cámaras a modo de contrafuertes para consolidar el exterior del muro perimetral (fig. 8a).

Los nichos-cámaras se asocian a rituales intratemplete, configurando un espacio vinculante con los fosos de las inhumaciones de infantes, los fogones estructurados y los diseños rupestres, que en conjunto se integran en cada estructura interior del templete (Núñez et al., 2006; 2017a). Presentan dinteles monolíticos bien conservados y/o alterados in situ, incrustados en el piso. En la base, bajo el dintel y sobre el piso, se han colocado bloques con caras planas, fragmentos de metates e incluso uno completo, que parecen haberse relacionado con algún ceremonial (figs. 8b y 8c). Tanto en jambas como en dinteles se han identificado sectores con pigmento rojo y grabados de cabezas de camélidos e incisiones, incluyendo aristas muy pulimentadas. Las aperturas de los nichos se sitúan sobre el piso y en ciertos casos en niveles más altos; en este caso, se dispusieron bloques en las bases. 


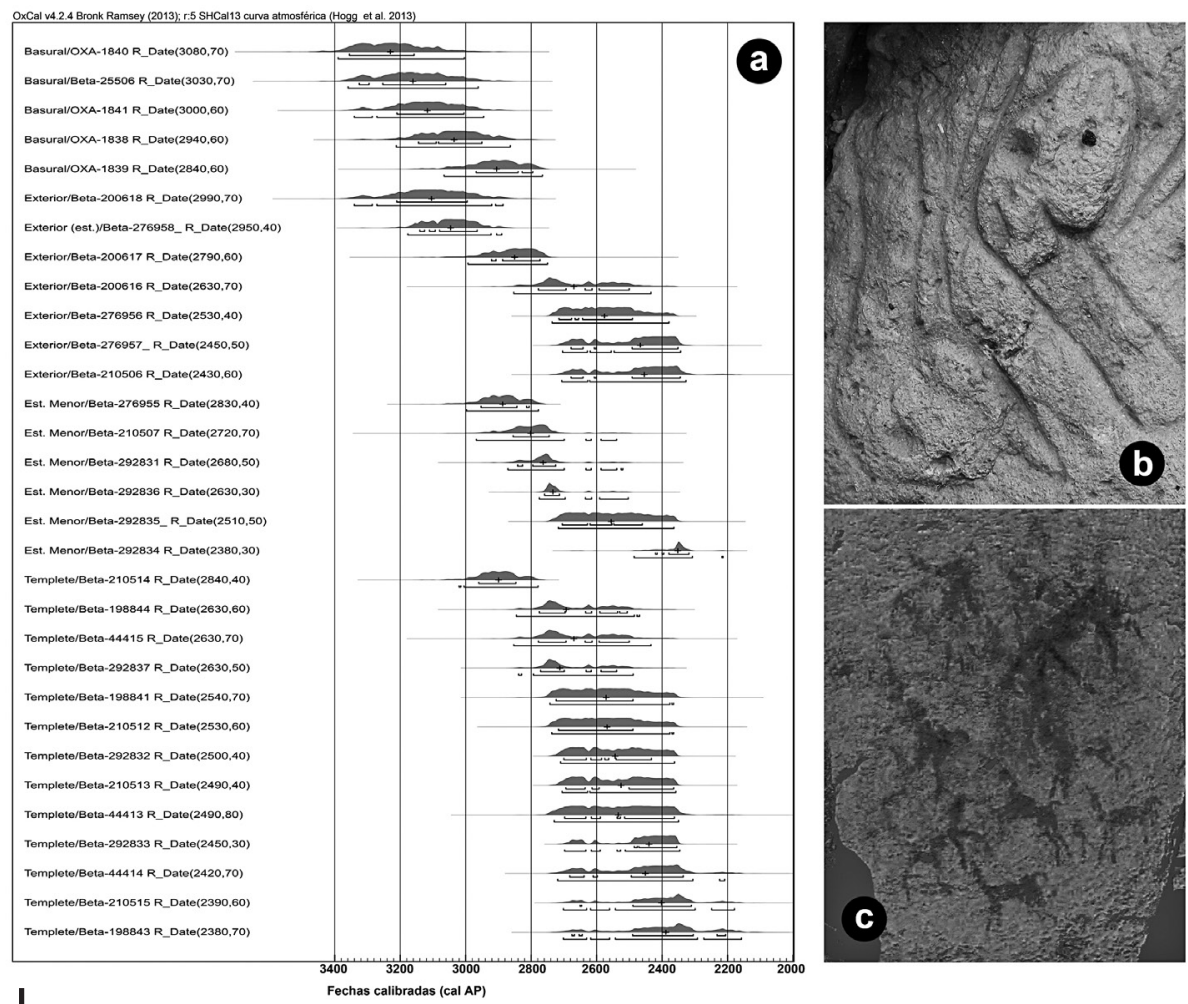

Figura 7 - (a) Dataciones calibradas obtenidas de los diferentes sectores del sitio Tulán-54

(b) Detalle de grabado de camélido con incisiones al interior del templete de Tulán-54

(c) Bloque con pictografía del estilo Confluencia al interior del templete de Tulán-54

Pictografía manipulada mediante D-Stretch-Image J (imagen facilitada por Wilfredo Faundes)

(C) Tomado y modificado de Núñez et al., 2017a: 9, 10, 34

Los nichos muestreados presentan restos culturales y de fauna a la entrada de cada cámara, donde se habrían socavado «bolsones» al interior de unos 25 a 30 $\mathrm{cm}$ para depositar las ofrendas desde el portal. Desde este sector se reconoce una parte mínima de los rellenos de las cámaras, compuestos por sedimentos finos estériles revueltos con escasos restos orgánicos y óseos, correspondientes a depósitos de descartes secundarios trasladados. Por lo mismo, no es posible constatar la naturaleza total de los rellenos, ni menos identificar con certeza lo que allí se depositó bajo el «techo» de las cámaras, las que no se excavaron por razones de conservación.

En consecuencia, solo se registró lo observado al interior inmediato de cada nicho. Al registrar con harneros finos y muestras de flotación los materiales concentrados en estos «bolsones», se observaron con mayor o menor intensidad descartes de alimentos, artefactos, fogones y residuos de labores. Se notan restos de talla lítica, de vegetales, carbones, ceniza, semillas carbonizadas, puntas de proyectiles, 


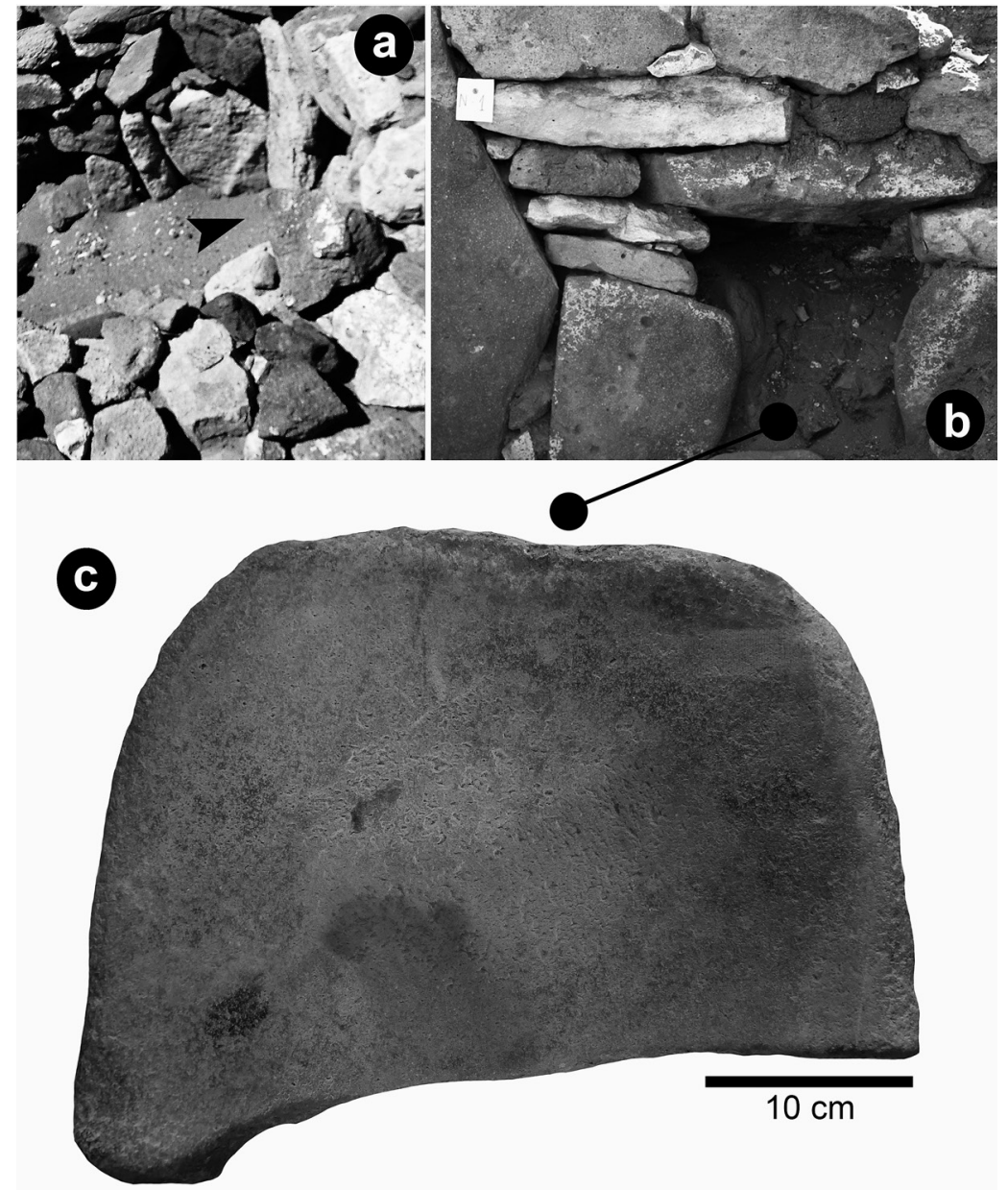

Figura 8 - (a) Detalle del nicho $n .^{\circ} 13$ a la entrada de la cámara

La flecha marca la ubicación del nicho

(b) El nicho $n .^{\circ} 1$ está asociado a la ofrenda de un metate en la base de su entrada.

(c) Detalle del metate registrado en el nicho $n .^{\circ} 1$

(C) Lautaro Núñez A.

fragmentos de cerámica y principalmente restos de huesos de camélidos (cuadro 1): al revisar los perfiles de los depósitos estratificados sobre el piso del templete, frente a los nichos, se observaron dos clases de residuos. Aquellos resultantes de actividades in situ, como fogones y lentes estratificados, y otros derivados de descartes secundarios trasladados desde el exterior del templete que incluyen restos culturales y alta presencia de huesos de camélidos procedentes de festines y desechos de utillaje.

Se podría interpretar como un escurrimiento del material arqueológico desde el piso del templete hacia el interior de los nichos, pero de ser así estos 
Cuadro 1 - Registros culturales de los nichos numerados

( $\mathrm{LM}=$ Los Morros, SP-NP=San Pedro Negro Pulido)

\begin{tabular}{|c|c|c|c|c|c|c|c|c|c|c|c|c|}
\hline LÍTICO & 1 & 2 & 5 & 6 & 7 & 8 & 9 & 10 & 11 & 12 & 13 & Total \\
\hline Preforma punta bifacial, obsidiana & & & 1 & & & & & & & & & 1 \\
\hline Cuchillo bifacial, basalto & & 1 & 1 & & & & & & & & & 2 \\
\hline Cuchillo (fragmento), lasca, toba & & 2 & 1 & & & & & & & & & 3 \\
\hline Pulidor-percutor, rodado, basalto & & & 1 & & & & & & & & & 1 \\
\hline Lasca unifacial, basalto & & 1 & 2 & & & & & & 2 & & & 5 \\
\hline Lasca filo con ocre, basalto & & & 1 & & & & & & & & & 1 \\
\hline Lasca filo usado, basalto, sílice & & 2 & 1 & & & & & & & & 1 & 4 \\
\hline Microperforador, sílice, obsidiana & & 2 & 8 & 7 & & 1 & & & 1 & & & 19 \\
\hline Desecho percusión, obsidiana, toba, sílice, basalto & & 4 & 220 & 57 & & & & & 3 & & & 284 \\
\hline Núcleo (fragmento), obsidiana & & & 2 & & & & & & & & & 2 \\
\hline Punta pedunculada, sílice, obsidiana & 1 & 1 & & 1 & & 1 & & & & & & 4 \\
\hline Núcleo (fragmento), toba, sílice & & 1 & & 1 & & 1 & & & & & & 3 \\
\hline Lasca no modificada, basalto, toba & & & & 3 & & & & & 2 & & & 5 \\
\hline Lámina filo usado & 2 & 2 & & & & & & 3 & 3 & 1 & & 11 \\
\hline Lasca modificada, obsidiana & & & & & & & & 3 & 3 & 2 & & 8 \\
\hline \multicolumn{13}{|l|}{ CERÁMICA } \\
\hline Negra pulida delgada (fragmento) SP-NP & & & 1 & & & & & & & & & 1 \\
\hline Cerámica corrugada (foránea NOA) & & & 1 & & & & & & & & & 1 \\
\hline Café-gris (fragmento), desgrasante grueso LM & 1 & 5 & & 1 & & & & & 2 & 1 & 1 & 11 \\
\hline Café-gris pulida borde engrosado, completa LM & & & & 1 & & & & & & & & 1 \\
\hline Café-gris pulida borde engrosado (fragmentos) LM & & & & 4 & & & & & & & & 4 \\
\hline \multicolumn{13}{|l|}{ ORNAMENTO } \\
\hline Cuenta hueso & & & & 3 & & & & & & & & 3 \\
\hline Cuenta lítica & & 1 & 1 & & & & & & & & & 2 \\
\hline Cuenta mineral cobre (fragmento) & & & 3 & 1 & & & & & & & & 4 \\
\hline Cuenta concha oriental (fragmento) & & & 1 & & & & & & & & & 1 \\
\hline Cuenta turquesa pulida (fragmento) & & & 1 & & & & & & & & & 1 \\
\hline \multicolumn{13}{|l|}{ MISCELÁNEA } \\
\hline Fibra lana torcida & & & 1 & & & & & & & & & 1 \\
\hline Huevo parina, golpe fuego (fragmento) & & & 4 & 1 & & & & & & & & 5 \\
\hline Hematita (fragmento) & & & 3 & & & & & & & & & 3 \\
\hline Pigmento rojo concrecionado & & & 1 & 2 & & & & & & & & 3 \\
\hline Concha oriental (fragmento) & & & 4 & & & & & & & & & 4 \\
\hline Mineral de cobre (fragmento) & & 5 & 23 & 8 & & & & & 1 & & & 37 \\
\hline Concha choro, pigmento rojo (fragmento) & & & & & & & & 1 & & & & 1 \\
\hline Plataforma lítica, pigmento rojo & & & & & & & & & 1 & & & 1 \\
\hline Madera cactus & & & & & & & & & & 1 & & 1 \\
\hline Pulidor lámina, toba & & 1 & & & & & & & & 1 & & 2 \\
\hline Tapón lítico, pulido & & 1 & & & & & & & & & & 1 \\
\hline Lasca plataforma, resto orgánico & & 1 & & & & & & & & & & 1 \\
\hline TOTAL & 4 & 30 & 281 & 90 & 0 & 3 & 0 & 7 & 18 & 6 & 2 & 441 \\
\hline
\end{tabular}

deberían reflejar una clara diversidad de contenidos. Es decir, si la capa que se encuentra frenta a un nicho es de ceniza, su expansión hacia el interior debería responder a ese residuo. Por otra parte, todos los nichos presentan restos óseos y no todos los estratos inferiores del templete los contienen. Por lo anterior, las oquedades registradas y las ofrendas asociadas reflejarían acciones que se esperarían encontrar en el caso de los rituales asociados a los nichos. La evidencia del traslado de descartes secundarios mezclados al interior de los nichos se ha verificado en un bloque estratigráfico que cubre toda la secuencia del templete, donde se ha observado la mezcla de capas limítrofes entre sí por el arrojamiento de fragmentos cerámicos que ensamblan, demostrándose mezclas 
entre los estratos. Además, durante el esparcido ritual sobre el piso del templete se habrían incluido selectivamente fragmentos más pequeños, posiblemente resultantes de piezas «matadas» (Schiffer, 1987; 1991; Kalazich, 2006). En suma, los descartes intranicho, a diferencia de las basuras domésticas convencionales, serían ofrendas dispuestas en ciertos espacios intratemplete, incluidos los nichoscámaras (Eliade, 1979).

\section{ANÁLISIS Y CRONOLOGÍA DE LAS OFRENDAS INTRANICHOS}

En los nichos muestreados se registraron 441 restos culturales y de fauna con frecuencias variables. Se identificaron, además, desechos de percusión, minerales de cobre ornamental, microperforadores, cuentas, fragmentos cerámicos, restos de conchas marinas y terrestres del oriente, incluidos huevos de parina (Phoenicoparrus andinus), algunos con golpe de fuego, pigmentos, piedras con ocre, hematita brillante, puntas pedunculadas, artefactos líticos varios y abundantes residuos óseos (cuadro 1). La cerámica registrada es similar a aquella de la fase Tilocalar del Formativo Temprano, ampliando considerablemente la popularidad y la escala espacial del tipo Los Morros (Sinclaire et al., 1997; Kalazich, 2006). Corresponde a la tradición Tulán-Los Morros que aparece durante la fase transicional Tarajne de 3715-3560 a 3460-3200 cal. AP (1765-1610 a 1510-1250 cal. a. C.), ampliándose su uso en la fase posterior Tilocalar, durante el desarrollo del templete Tulán entre 3450-3080 y 2410-2370 cal. AP (1500-1130 a 460-520 cal. a. C.).

En todos los nichos testeados se señalaron fragmentos cerámicos correspondientes a tiestos reconocidos en el templete, donde predominan las vasijas de uso doméstico con tiznados, alisadas y pulidas de paredes gruesas y escasos fragmentos delgados pulidos y bruñidos sin golpes de fuego, que darían lugar a la tradición negra pulida de San Pedro de Atacama. Se acepta que estos tiestos tratados con fines quizás ceremoniales acompañaban a los tiestos domésticos mayoritarios desde los inicios de la ocupación del templete, vinculados con almacenamiento, comidas y brebajes ritualizados. Su uso allí derivó de estas actividades y mayormente de su traslado como descarte con fines ceremoniales desde el exterior; no se observan diferencias entre los tiestos dentro o fuera del templete (Kalazich, 2006).

Los escasos fragmentos corrugados intranicho (2), como los cordelados y unguiculados del comienzo de la ocupación del templete, provendrían de las tierras bajas del noreste argentino, junto con alucinógenos del cebil (Anadenanthera colubrina) y conchas para cuentas y pendientes (Strophocheilus oblongus), ofrendados en las inmolaciones de infantes intratemplete. La mayor parte de los fragmentos cerámicos registrados corresponde al tipo Los Morros de amplia distribución local (Sinclaire et al., 1997). La vasija del nicho n. ${ }^{\circ} 6$ asociada a restos de huesos de camélidos y datada en 2640 AP / 2765 a 2715 cal. AP (815 a 765 cal. a. C.), representa el mismo reborde bucal engrosado, una de las formas más recurrentes desde los primeros eventos datados en el piso del templete (Núñez et al., 2017b). En el mismo nicho se registraron dos mitades de una misma vasija 
que fue «matada», a diferencia de los fragmentos registrados en los otros nichos que no constituyen partes de alguna pieza específica (figs. 9a y 9b). Su asociación directa con el tiesto antes datado admite su plena sincronía con evidencias de uso doméstico a juzgar también por su base tiznada con hollín adherido. Se trata de una olla de cuerpo globular de superficie gris con alisado homogéneo, con un asa, de cuello corto y con el típico reborde bucal. Corresponde a las grandes vasijas frecuentes en el sitio, con boca amplia, con un diámetro máximo de $28 \mathrm{~cm}$ y una altura ca. de $25 \mathrm{~cm}$, con el fondo estriado por posibles huellas de raspado (fig. 9c).
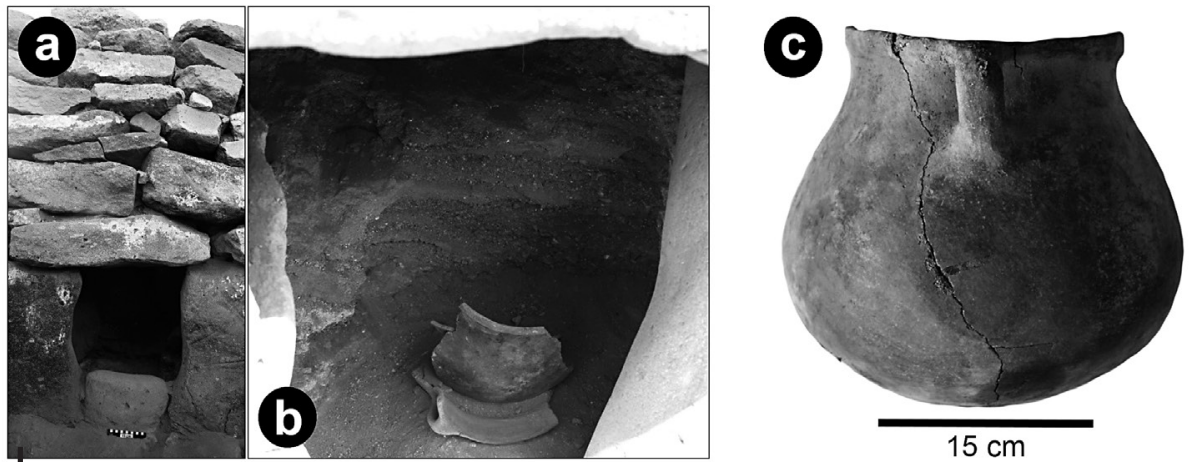

Figura 9 - (a) y (b) El nicho $n .^{\circ} 6$ contenía en su interior una vasija fracturada en dos partes

(c) Su forma es representativa del templete

(C) Lautaro Núñez A.

Como en el caso anterior, el fragmento datado con reborde bucal, se asocia a tres fragmentos menores de la misma pieza. Se caracteriza por una superficie expuesta de un modo más recurrente a la acción del fuego con un tiznado grueso generalizado. Bajo partes del hollín se reconoce la superficie original café clara con áridos típicos gruesos. A juzgar por el diámetro bucal del orden de los 29,5 cm se reconoce una olla similar al caso anterior. En el test estratigráfico de los sectores aledaños se ha observado ca. de un 50\% de hollín en los tiestos analizados, donde se han ubicado fragmentos similares de bases convexas como ollas de bocas amplias a juzgar por sus diámetros entre 24-30 cm (Kalazich, 2006). Solo se registró un fragmento de cerámica San Pedro Negro Pulido que, si bien ya se encuentra presente durante el Formativo Temprano, es muy escasa en los sitios. Sin embargo, alcanza una alta popularidad durante el Formativo Tardío atacameño (Tarragó, 1989).

El material lítico es muy abundante, compuesto tanto de desechos como de artefactos. Se destacan las ofrendas de puntas pedunculadas de proyectiles no usadas, similares a las del interior del templete. El resto del conjunto artefactual es muy similar al observado en los rellenos del templete donde abundan los microperforadores, cuchillos y lascas con filo natural utilizado. Por su parte los desechos corresponden también a materias primas identificadas con anterioridad en el sitio (Núñez et al., 2006; 2007). 
El análisis de flotación aplicado al contenido del nicho n. 5 ha permitido identificar un total de 252 restos (cuadro 2). La mayoría de ellos corresponde a pequeños fragmentos de madera carbonizada (tamaño menor a $5 \mathrm{~mm}$ ). Le siguen dentro del conjunto identificado los restos botánicos de la familia Asteraceae, sin determinación de especie. Sin embargo, es necesario considerar que los análisis preliminares realizados indican que las especies de la familia Asteraceae por lo general son numerosas, de modo que se presentan varios aquenios en una misma planta. Se estima que lo representado en las muestras puede corresponder solo a un máximo de 2-3 plantas de una de las especies de la familia. Se registró a su vez un fragmento de semilla de Opuntia sp. carbonizada y una semilla carbonizada de la familia Malvaceae, sin determinación de especie. Se recuperaron partes de inflorescencias no identificadas y finalmente un porcentaje menor de restos no identifiacados de los cuales seis se encuentran carbonizados.

\section{Cuadro 2 - Restos vegetales recuperados por flotación del contenido del nicho $n .^{\circ} 5$}

\begin{tabular}{|l|c|}
\hline \multicolumn{1}{|c|}{ Restos vegetales } & N \\
\hline Madera carbonizada & 144 \\
\hline Asteraceae & 90 \\
\hline Opuntia sp. & 1 \\
\hline Malvaceae & 1 \\
\hline Inflorescencias no identificadas & 6 \\
\hline No identificados & 10 \\
\hline Total & $\mathbf{2 5 2}$ \\
\hline
\end{tabular}

Se analizaron un total de 797 restos óseos provenientes de los nichos n. ${ }^{\circ}$ 1, 2 , 5 y 6 ; en los dos últimos se encuentra el mayor número de restos. Predominan los restos de camélidos, donde algunas unidades anatómicas como el cráneo-mandíbula y vértebras cervicales se encuentran bien representadas, a diferencia del restante segmento vertebral y costillas escasamente registradas. Por su parte, el miembro anterior y posterior superior y medio alcanzan una mediana representación, a excepción de la cintura escapular. La extremidad inferior representada por metapodios y falanges alcanza una mayor representación con relación a las extremidades anteriores; sin embargo, un alto número de unidades y porciones de otras unidades se encuentran ausentes. En cuanto a la estructura etaria, se observa una alta representación del conjunto de animales jóvenes (no fusionados) en la mayoría de los nichos, alcanzando el 54\% (en términos de Número Mínimo de Elementos Óseos) donde la mayoría de los especímenes son menores de 24 meses. En el nicho $n .^{\circ} 2$, se registró además un perinato, probablemente nonato (feto). Llama la atención en el nicho $\mathrm{n} .^{\circ} 1$ la presencia de huesos de la extremidad anterior de un zorro culpeo (Lycalopex culpaeus), en general muy poco representado en el sitio. Además, en el nicho $\mathrm{n} .^{\circ} 2$ se recuperó un espécimen de gran tamaño en el rango de las Ilamas actuales que podría corresponder a un morfotipo carguero. Los restos presentan baja remontabilidad anatómica y mecánica; ahí la mayoría son producto del descarte posprocesamiento para carne, médula y formatización 
de artefactos. Estos descartes son entonces el resultado de un variado número de actividades y corresponderían principalmente a restos secundarios que podrían estar obliterando otras actividades in situ (Cartajena et al., 2018).

En el nicho n. 12 y en un momento en que la acumulación de descartes no alcanzó a cubrir su parte superior, se introdujo el cráneo y parte de la caja toráxica de un cuerpo adulto (figs. 10a, 10b y 10c). El resto del esqueleto, a nivel del cráneo, quedó expuesto fuera del nicho. La datación de uno de los nichos del orden de 815-765 a. C. se considera sincrónica con otras fechas del templete, con variaciones dentro del rango. Los rasgos a nivel del piso del templete cercanos a los nichos se han datado previamente en el fogón estructurado $\mathrm{n}$. $^{\circ}$ correspondiente a 2630 AP / 2850 a 2720 cal. AP (900-770 cal. a. C.). El foso con los infantes 11 y 12 se fechó a los 2550 AP / 2780 a 2370 cal. AP (820 a 420 cal. a. C.), mientras que el infante n. 23 se fijó en 2530 AP / 2760 a 2370 cal. AP (810 a 420 cal. a. C.). Una reciente datación del comienzo de la ocupación fuera del templete se ha determinado a los 2540 AP / 2735 a 2465 cal. AP (785 a 515 cal. a. C.). De modo que se esperaría que entre los eventos fundacionales datados los nichos fueran parte de la ritualidad inicial. Por otra parte, al observarse la reiteración del patrón de ofrendas, es posible que la mayoría se dispuso en torno a la datación del nicho $\mathrm{n} .^{\circ} 6$.
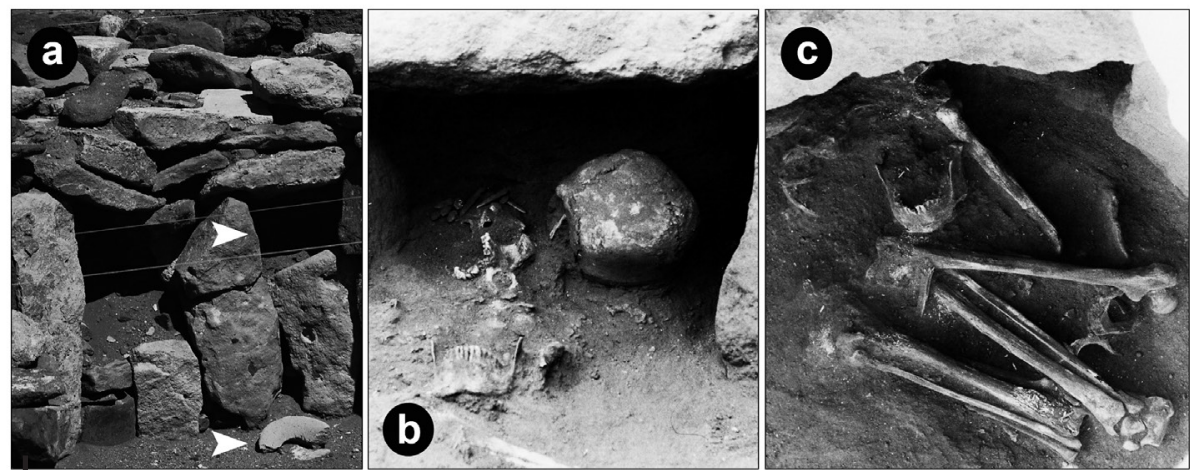

Figura 10 - (a) Los nichos $n .^{\circ} 12$ y 13

La flecha superior indica el espacio donde se registró la inhumación de un adulto (nicho 12), cuando el templete se encontraba en proceso avanzado de colmatación. Corresponde a una modalidad más elevada con una ofrenda de fragmento de metate agotado en su base, indicado por la flecha inferior

(b) Ubicación del cráneo, vertebras y maxilar inferior dentro del nicho

(c) Parte del tórax y de las extremidades inferiores fuera del nicho

(C) Lautaro Núñez A.

\section{ANÁLISIS DE LAS CÁMARAS}

Las cámaras o estructuras abovedadas se asocian con los nichos cuyos contenidos se desconocen; en efecto, se optó por no alterar la evidencia constructiva que requiere de un tratamiento de anastilosis adecuado (fig. 11). Para una aproximación 


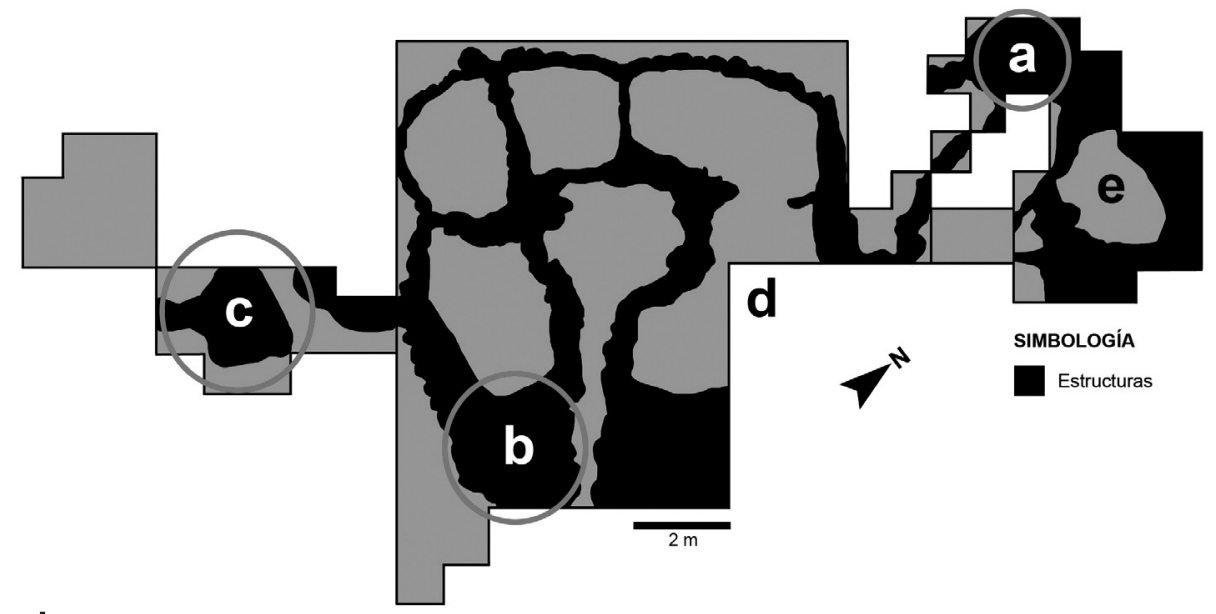

Figura 11 - Esquema de las excavaciones del templete y su entorno. (a) Cámara n. ${ }^{\circ} 1$

(b) Cámara n. ${ }^{\circ} 2$ (no excavada)

(c) Exposición de los «techos» de las cámaras y acumulamientos de soporte del muro perimetral, correspondientes a los nichos 12, 13, 14 y 15

(d) Bloque testigo del depósito estratigráfico no excavado

(e) Estructura de uso ceremonial con nichos, asociada al templete central

(c) Patricio López M.

se evaluaron dos cámaras situadas fuera del templete. La $\mathrm{n} .^{\circ} 1$ se encuentra cerca de una estructura menor con atributos similares a los del templete central, también provista de nichos. La cámara n. $^{\circ} 2$ es una estructura ovoidal sellada, localizada al SE del templete, excavada en bloque en todo su entorno (fig. 12). Por su magnitud y consolidación, se decidió dejarla como testigo.

Se ha planteado que a cada nicho le corresponde una cámara, de modo que habría 15 bóvedas apegadas al exterior del muro perimetral del templete. La extracción de los sedimentos superficiales sobre sus cubiertas demostró en el caso de los nichos n. ${ }^{\circ} 12$ y 13 que junto a las lajas de los «techos» se dispusieron bloques que ocuparon una amplia faja de rocas, permitiendo, además, la contención exterior del muro perimetral. La cámara $n .^{\circ} 1$ presenta una escala más restringida «techada» con lajas seleccionadas y canteadas que la sellan, incluyendo un diseño antropomorfo pictografiado en rojo. Una vez retiradas, se procedió a excavar el relleno interior compuesto por sedimentos con residuos finos orgánicos y abundantes restos óseos astillados, principalmente metapodios de camélidos, correspondientes a descartes trasladados de áreas de actividades externas, siguiendo el patrón ritual de los contenidos de los nichos. Al interior de la cámara el cráneo estaba orientado al Sur y el cuerpo muy desarticulado en un eje N-S, notándose la ausencia de las extremidades inferiores. La ubicación de un pequeño fogón situado a un costado del cráneo sugiere un ritual que antes se había notado en el infante $n .^{\circ} 23$, ofrendado en un foso al interior del templete. 


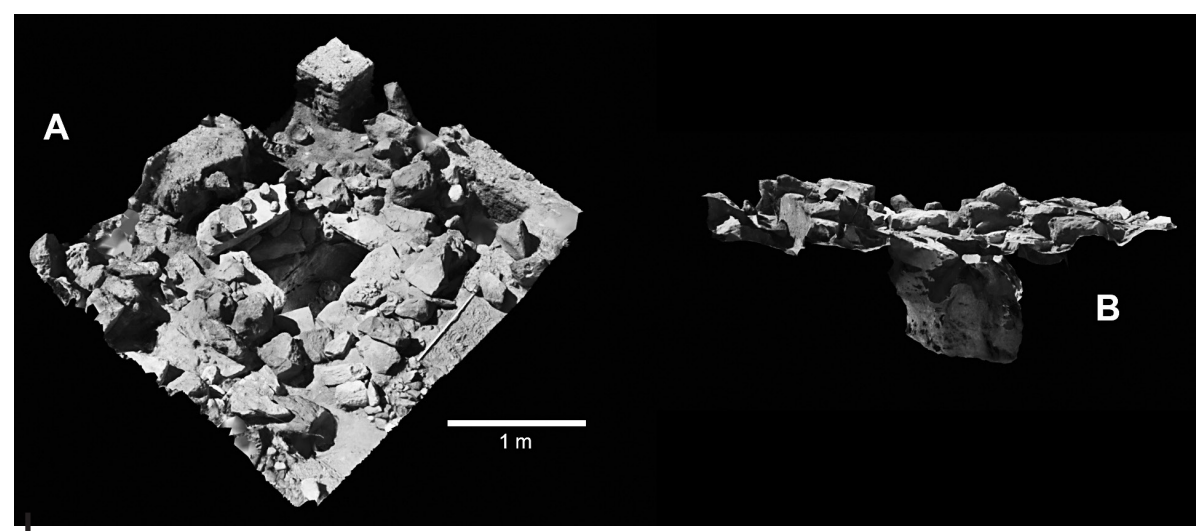

Figura 12 - Fotogrametría de la cámara n. 1 durante su proceso de excavación, asociada a la estructura ceremonial aledaña al templete central

(a) Vista superior y (b) vista de la sección

(C) Fotogrametría realizada por Pablo Gómez

El infante de la cámara n. ${ }^{\circ} 1$ estaba asociado a las siguientes ofrendas: masa de pigmento rojo, roca con ocre, seis desechos de percusión de sílice, cinco desechos de obsidiana, una de cristal de roca, tres restos óseos mínimos carbonizados, una cuenta rectangular plana de turquesa en proceso de perforación, un fragmento de costilla de camélido con bordes pulidos y una espátula o punzón de hueso fracturado. Presenta en los extremos proximal y distal (aguzado) restos orgánicos y huellas de estrías paralelas finas. Al comparar esta inhumación con los otros infantes ofrendados en el templete, se nota la carencia de objetos sofisticados, como los laminados de oro. Su colocación desarticulada con ausencia de las extremidades inferiores indicaría que fue manipulado, trasladado o recolocado al interior de la cámara (Standen et al., Ms.; Núñez et al., 2017a; b).

La datación de la segunda costilla izquierda señala que el ritual ocurrió por los 2600 AP / 2750 a 2700 cal. AP / 2630 a 2620 cal. AP y 2560 a 2540 cal. AP (800 a 750 cal. a. C.). De este modo se propone que en las cámaras del templete se hayan dispuesto otros infantes que, por razones desconocidas, no se situaron en los fosos intratemplete, y tampoco en el cementerio cercano al centro ceremonial (Tulán-58). De hecho, el infante de esta cámara es sincrónico con los infantes dispuestos en los fosos del templete. Es posible que estas cámaras, asociadas a nichos o portales, hayan pervivido en el tiempo, esta vez transformadas en bodegas que caracterizarían a las poblaciones locales del Intermedio Tardío. En el asentamiento inca de Peine Viejo se observa este patrón constructivo caracterizado, precisamente, por los «techos» con grandes lajas y bloques superpuestos, correspondientes a «bóvedas falsas» (fig. 13). 


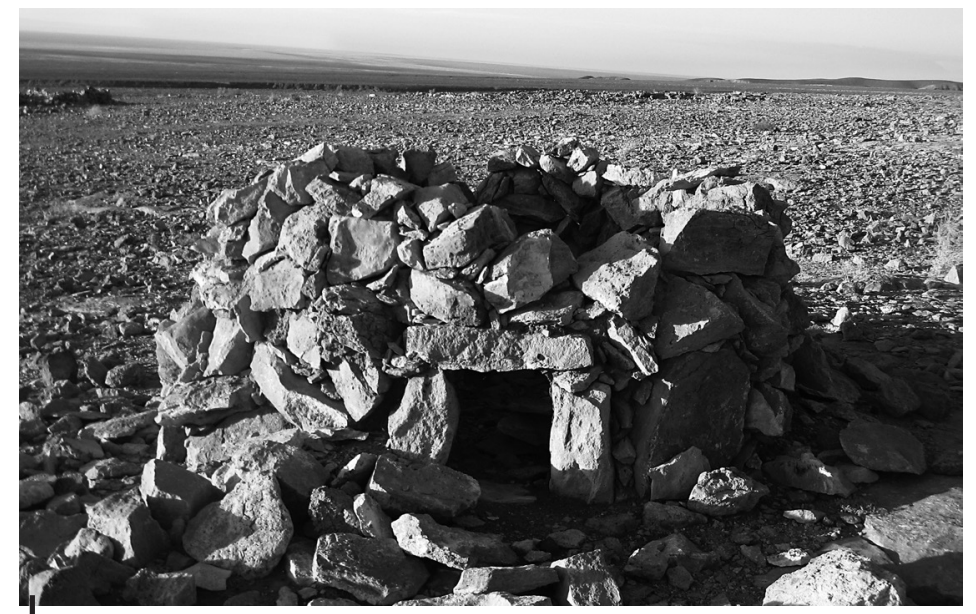

Figura 13 - Bodega que caracteriza al asentamiento inca Peine Viejo, compuesta por un portal como nicho con cámara «techada» (falsa bóveda)

Se trataría de un patrón constructivo local, posiblemente derivado de las ocupaciones formativas que persisten hasta la ocupación inca

(C) Fotografía tomada por Francisco Rivera

\section{ANTECEDENTES ETNOGRÁFICOS ANDINOS SOBRE LAS COMIDAS RITUALIZADAS}

La alta frecuencia de restos cerámicos y de camélidos consumidos extra e intratemplete que forman parte de los depositados al interior de los nichos, responde a actividades rituales vinculadas con festines recurrentes en el altiplano, incluyendo la Circumpuna durante eventos formativos (Hastorf et al., 2001; Núñez et al., 2016; 2017a; 2017b, entre otros). Son expresiones de tempranas cosmovisiones pastoralistas de las tierras altas y, por lo mismo, sujetas a ser examinadas desde testimonios etnográficos aimaras, entre los cuales hay consenso que las comidas y bebidas adquirieron un valor ceremonial. Wakas, deidades tutelares, fuerzas de la naturaleza como las montañas, el espíritu del ganado salvaje y doméstico: todos comen. Se les satisface con ofrendas en «mesas» y sacrificios, incluyendo el culto a antepasados míticos, con el fin de evitar sus reacciones adversas. De acuerdo con los pastores, la mayor deidad son los Apus masculinos que habitan en las profundidades de las montañas nevadas, dueños de los animales salvajes y domésticos, de modo que para asegurar su multiplico es necesario satisfacerlos con comidas y bebidas sacralizadas (Girault, 1984; 1987; 1988; Martínez, 1983; Scanu, 1987; Fernández Juárez, 1994; Macquarrie, 1995). Estos poderes protectores acogen las rogativas en torno a la caza y crianza de camélidos, entre comunidades que percibieron ese escenario cordillerano como un ámbito medio salvaje (Lecoq \& Fidel, 2000; Walter, 2002). Sin embargo, también ejecutan actos de reciprocidad con las entidades de las Chullpas o sus 
«gentiles» prehispánicos inhumados, que por ser distinguidos como sus ancestros, han implicado rituales específicos (Fernández Juárez, 1994).

Los pastores altiplánicos organizan encuentros durante el ciclo anual para que ciertas deidades tutelares (Conopas) no sientan hambre y con ello puedan liberarse de castigos poderosos. Son voraces, capaces de alimentarse con humanos y por lo tanto ameritan ser tratadas bajo rigurosos pactos de reciprocidad (Rasnake, 1989). Sobre fogones se preparan platos abundantes de comida y se esparcen a la tierra las bebidas fermentadas. Mientras tanto se han observado señales en las vísceras de la llama sacrificada, en el humo y en el color de las cenizas para asegurar que el «banquete» ha sido bien acogido (Delgado Aragón, 1971; Fernández Juárez, 1994; Macquarrie, 1995). De no ser así y si dominan las cenizas oscuras, será necesario preparar mejor el fogón con más alcohol. Los platos servidos también se queman entre libaciones para espantar a los espíritus malignos. Se ha examinado el corazón y los pulmones de los camélidos para indagar cómo se ha acogido el ritual. Después trasladan el resto de las comidas a sus viviendas, a modo de agradecimiento por el pago cumplido. Finalmente, las mujeres retiran los huesos de las presas, los que son quemados en sus residencias antes de la noche (Tomoeda, 1993; 1996; Macquarrie, 1995; Stobart, 2002). Es importante subrayar que ciertas partes de los animales sacrificados son utilizadas como ofrendas para transferir las fuerzas vitales hacia una habitación u otras estructuras para recibir desde allí un mayor bienestar (Arnold, 1992). Por su parte, los uros del altiplano meridional levantaban los postes de sus habitaciones sobre cuerpos de niños, cuya sangre era valorada como alimento para el sol (Posnansky, 1938).

Al respecto, durante el rito del «llamado a las lluvias», observado en el año 2010 entre los aimaras tarapaqueños de Chulluncane (Cariquima), la familia Challapa hizo una ofrenda al cerro T'alla Justina en un gran cántaro (isla C'owa), aguas del lago Titicaca mezcladas con otras contenidas en dos tiestos menores, trasladadas desde el Pacífico. Allí se procedió a sacrificar una llama blanca juvenil, esparciendo la sangre hacia los cerros sagrados (Malkus), auspiciando las lluvias sobre la $T^{\prime}$ alla Wanapa (hembra). Terminada la comida ritual, el fogón se mantuvo in situ, mientras se «challaba» alcohol sobre el espacio ritual y los huesos descartados se recogían cuidadosamente para ser trasladados a las casas (M. Núñez, 2015). Durante estos «llamados» los huesos restantes de las comidas ritualizadas se entierran en los corrales para auspiciar el multiplico del ganado (Bolin, 1998).

\section{CONCLUSIONES}

De acuerdo a los antecedentes antes mencionados es posible observar que la realización de encuentros y festines de manera recurrente tienen el potencial de generar un abundante cúmulo de restos relacionados con las diversas actividades Ilevadas a cabo, tanto al exterior como al interior del templete. Muchos de estos restos fueron intencionalmente utilizados para colmatar progresivamente el templete. Sin embargo es necesario considerar el momento inicial de ocupación del templete previo a la colmatación donde operaron numerosos rituales en 
torno a los entierros de los infantes, quemas en fogones estructurados, pozos de ofrendas, y la realización de grabados y pinturas rupestres, la mayoría de ellos dispuestos cerca de los nichos.

El estudio de los nichos y de las cámaras nos permiten ampliar el conocimiento de otras estructuras propias del templete que no habían sido analizadas con anterioridad. El contenido de la cámara excavada sugiere que aquellas que rodean el muro perimetral contendrían infantes. No es posible establecer que las ofrendas dispuestas en los socavados de los nichos se vinculen con el contenido de las cámaras.. A partir del análisis de los nichos, Ilama la atención que los restos recuperados sean muy similares a los que componen el relleno del templete. Algunas excepciones se han observado en un nicho, en donde se depositó parte de un cuerpo humano adulto una vez que el templete haya estado en proceso de colmatación. En el nicho $n .^{\circ} 6$ se registró una vasija completa «matada» en dos partes y un metate en el nicho . $^{\circ} 1$, depositados cuando se iniciaba el tapado del piso.

Si bien no es posible establecer la función y el contenido de los nichos previos al proceso de relleno del templete, estos pudieron albergar elementos utilizados durante los rituales, como semillas, figurillas u otros objetos de culto (Onuki, 1993; Quilter, 2014). Si bien no se conoce qué elementos podrían haber contenidos los nichos, la estratigrafía al interior de los mismos sugiere que en un primer momento los sedimentos han contenido escasos restos óseos y artefactuales. No obstante y probablemente en forma sincrónica, cuando comienzan a colmatarse los recintos del templete empiezan a rellenar también los nichos. En este momento se introducen tiestos muy rotos derivados del ritual del «matado» o fin de la «vida» útil de las piezas, junto con numerosos restos óseos, líticos, cuentas, fragmentos de cerámica y mineral de cobre entre otros (Núñez et al., 2017a; b).

Los restos óseos faunísticos pertenecerían a distintos eventos de deposición, debido a una gran diversidad de rangos etarios, baja remontabilidad anatómica y mecánica, diversos estadios de meteorización y a la presencia de camélidos, tanto del grupo grande como pequeño.

La mayoría de los restos son producto del descarte posprocesamiento para carne, médula y formatización de artefactos, principalmente de carácter secundario. Estos son muy similares a los restos registrados en el relleno de las diversas estructuras del templete; sin embargo, podrían estar enmascarando restos primarios producto de actividades in situ como, por ejemplo, la disposición de los restos del carnívoro antes mencionado o el consumo ritual. Por su parte, gran parte de los restos vegetales recuperados se encuentran carbonizados ya sean pequeños fragmentos de madera o semillas de Malvaceae, lo que sugiere la presencia de fogones, productos de la utilización de leñosas o arbustos o bien de la quema de plantas herbáceas (Asteraceae). Por otra parte, la determinación de una semilla de Opuntia sp., aunque con mínima representatividad, se vincula con las determinaciones que para el mismo sitio se han efectuado con anterioridad (Núñez et al., 2009b; Planella, 2017). La ausencia de macrorrestos de cultígenos como Zea mays, Chenopodium quinoa, y Lagenaria sp., al interior de los nichos 
como en el templete en general, indica que eran usados selectivamente, lo que confirma que durante la fase Tilocalar el rol subsistencial de la agricultura no era relevante (Holden, 1991; Núñez et al., 2009b; Planella, 2017). Finalmente, elementos provenientes tanto de diferentes zonas ecológicas como de regiones distantes (cáscara de huevo de parinas, conchas de la selva trasandina y del Pacífico y obsidiana, entre otros), no son exclusivos de los nichos sino que han sido igualmente constatados en el interior del templete.

Con respecto a la relación entre nichos y cámaras se propone que el contenido de las bóvedas, posiblemente infantes, hayan recibido a través de los nichos ofrendas adicionales colocadas desde el interior del templete. Se ha planteado que las inmolaciones de los veinticuatro infantes en los fosos a nivel del piso del templete se relacionan como intermediarios entre las rogativas locales y las deidades (Núñez et al., 2006; 2017a). El registro sincrónico de un infante excavado en la cámara n. ${ }^{\circ} 1$, aunque difiere por sus ofrendas menos complejas de aquellos del templete, podría responder a similares propósitos, sugiriéndose con ello que las cámaras no excavadas pudieran también contener inhumaciones infantiles.

Los nichos-cámaras se habrían incorporado a una arquitectura compleja que admitió actos que aspiraban a un equilibrio en términos de rogativas y protección, y que aún persisten en los testimonios pastoralistas etnográficos, donde el rol de las comidas y bebidas fue determinante para estimular la participación social (Fernández Juárez, 1994; Rosïng, 1994; Fernández Juárez, 1995; BouysseCassagne \& Harris, 1987; Núñez et al., 2006). La presencia en los nichos de descartes de comidas, utillaje asociado, restos artefactuales, además de ciertas ofrendas vinculantes (vasija, metates e inhumaciones), indica que estos fueron compartidos entre los humanos y las deidades. Estos ritos se habrían sumado a la intermediación asignada a los infantes y adultos enterrados en el centro ceremonial para establecer conexiones y rogativas con sus ancestros y el panteón circumpuneño.

\section{Agradecimientos}

Los autores agradecen el permanente apoyo recibido de la comunidad de Peine, de sus autoridades, asistentes en terreno y en el tratamiento de las colecciones. Se agradece así mismo a todos los investigadores del proyecto FONDECYT 1130917 y a nuestra colega Bárbara Rivera por su ayuda en la traducción de parte del texto.

\section{Referencias citadas}

ADÁN, L. A. \& URBINA, S. A., 2007 - Arquitectura formativa en San Pedro de Atacama. Estudios Atacameños, 34: 7-30.

AGÜERO, C. \& URIBE, M., 2011 - Las sociedades formativas de San Pedro de Atacama: asentamiento, cronología y proceso. Estudios Atacameños, 42: 53-78.

ALVA MENESES, I., 2012 - Ventarrón y Collud: origen y auge de la civilización en la costa norte del Perú. Proyecto especial Naylamp Lambayeque, 301 pp.; Lambayeque: Ministerio de Cultura, Proyecto especial Naylamp-Lambayeque. 
ARNOLD, D., 1992 - The house of earth-bricks and Inka stones: gender, memory and cosmos in Qaqachaka. Journal of Latin American Lore, 17 (1): 3-69.

BOLIN, I., 1998 - Rituals of Respect: The Secret of Survival in the High Peruvian Andes, 312 pp.; Austin: University of Texas Press.

BONNIER, E., 1987 - Les architectures précéramiques dans la Cordillère des Andes. Piruru face à la diversité des données. L'Anthropologie, 91 (4): 889-904.

BOUYSSE-CASSAGNE, T. \& HARRIS, O., 1987 - Pacha: en torno al pensamiento aymara. In: Tres reflexiones sobre el pensamiento andino (T. Bouysse-Cassagne, O. Harris, T. Platt \& V. Cereceda, eds.): 11-60; La Paz: Hisbol, Biblioteca Andina.

BUENO, A., 1998 - El Formativo Andino: Análisis, revisión y propuestas. Cantuta, 15: 1-9.

CANZIANI, J., 2009 - Ciudad y territorio en los Andes. Contribuciones a la historia del urbanismo prehispánico, 549 pp.; Lima: Fondo Editorial, Pontificia Universidad Católica del Perú.

CARRASCO, C., 2007 - Excavaciones en el Sitio TU-122 de la Quebrada de Tulán. Informe de avance de proyecto FONDECYT 1070040. Manuscrito no publicado.

CARTAJENA, I., NÚÑEZ, L. \& GROSJEAN, M., 2007 - Camelid domestication on the western slope of the Puna de Atacama, Northern Chile. Anthropozoologica, 42 (2): 155-174.

CARTAJENA, I., LÓPEZ, P. \& NÚÑEZ, L., 2018 - Los nichos en la arquitectura a inicios del Formativo: Una aproximación desde la fauna en el templete de Tulán-54 (Salar de Atacama, Chile). Manuscrito no publicado.

DE SOUZA, P., CARTAJENA, I., NÚÑ̃EZ, L. \& CARRASCO, C., 2010 - Cazadoresrecolectores del Arcaico Tardío y desarrollo de complejidad social en la puna de Atacama: las evidencias del sitio Tulán-52 (norte árido de Chile). Werkén, 13 (2): 91-118.

DELGADO ARAGÓN, D., 1971 - El Señalakuy: Departamento de Puno, Distrito de Macusani. Allpanchis Phuturinqa, 3: 185-197.

EECKHOUT, P., 1998 - Le temple de Pachacamac sous I'empire inca. Journal de la Société des Américanistes, 84 (1): 9-44.

ELIADE, M., 1979 - Lo sagrado y lo profano, 185 pp.; Barcelona: Guardarrama.

FERNÁNDEZ JUÁREZ, G., 1994 - “El banquete aymara”: aspectos simbólicos de las mesas rituales aymaras. Revista Andina, 12 (1): 155-189.

FERNÁNDEZ JUÁREZ, G., 1995 - El banquete aymara: mesas y yatiris, 570 pp.; La Paz: Hisbol.

GIRAULT, L., 1984 - Kallawayas, guérisseurs itinérants des Andes. Recherche sur les pratiques médicinales et magiques, 670 pp.; París: ORSTOM-CNRS, Collection Mémoire № 107.

GIRAULT, L., 1987 - Kallawaya: curanderos itinerantes de los Andes. Investigación sobre prácticas medicinales y mágicas, 670 pp.; La Paz: Unicef, ENE.

GIRAULT, L., 1988 - Rituales en las Regiones Andinas de Bolivia y Perú, ix + 467 pp.; La Paz: Edic. Don Bosco.

GUTIÉRREZ, F., 2006 - La arquitectura en quebrada de Tulán. Construcción de espacios para vivir. Informe de avance del Proyecto FONDECYT 1020316. Manuscrito no publicado.

HASTORF, C. A., BANDY, M., WHITEHEAD, W. T. \& STEADMAN, L., 2001 - El periodo Formativo en Bolivia. Regiones y sociedad. Textos Antropológicos, 13: 17-91. Con contribución de: D. Bloom, E. Dean, S. del France, R.I Goddard, D. Kojan, K. Moore, J. L. Paz Soria \& D. W. Steadman. 
HOLDEN, T. G., 1991 - Evidence of prehistoric diet from northern Chile: Coprolites, gut contents and flotation samples from the Tulán quebrada. World Archaeology, 22 (3): 320-331.

KALAZICH, F., 2006 - Tipología y contextos de uso de la alfarería temprana de Tulán (1200-400 AC), Puna de Atacama. Informe de Práctica Profesional. Universidad de Chile, Facultad de Ciencias Sociales, Departamento de Antropología, Santiago de Chile.

KALAZICH, F. \& UGARTE, M., 2008 - Análisis tipológico y depositacional de la alfarería de los sitios Tu-85 y Tu-122, Quebrada de Tulán, II Región de Antofagasta. Anexo de Informe de Avance, Proyecto Fondecyt 1070040. Manuscrito no publicado.

LECOQ, P. \& FIDEL, S., 2000 - Algunos aspectos de la vida y de los ritos ganaderos en Ventilla, una comunidad pastoril del Sud de Potosí, Bolivia. In: Pastoreo altoandino. Realidad, sacralidad y posibilidades (J. Flores Ochoa \& Y. Kobayashi, eds.): 149-187; La Paz: Plural, Musef.

MACQUARRIE, K., 1995 - Mitos, leyendas y ceremoniales: llamas, alpacas y dioses de las montañas. In: Oro de los Andes. Las llamas, alpacas, vicuñas y guanacos de Sudamérica (J. Flores Ochoa, K. MacQuarrie \& J. Portús, eds.): 195-209; Barcelona: Blassi.

MARTíNEZ, G., 1983 - Los Dioses en los Cerros de los Andes. Journal de la Société des Américanistes, 69: 85-115.

MUJICA, E., 1985 - Altiplano-coast relationships in the South Central Andes: from indirect to direct complementary. In: Andean ecology and civilization. An interdisciplinary on Andean ecological complementarity (S. Masuda, I. Shimada \& C. Morris, eds.): 103-140; Tokyo: University of Tokyo Press, Papers from Wenner-Gren Foundation for Anthropological Research Symposium n. ${ }^{\circ} 91$.

NúÑEZ, L., 2005 - La naturaleza de la expansión aldeana durante el formativo tardío en la cuenca de Atacama. Chungara, 37 (2): 165-193.

NúÑ̃EZ ATENCIO, L., CARTAJENA FASTING, M. I., CARRASCO GONZÁLEZ, C. A., DE SOUZA, P. \& GROSJEAN, M., 2006 - Emergencia de comunidades pastoralistas formativas en el sureste de la Puna de Atacama. Estudios Atacameños, 32: 93-117.

NÚÑEZ, L., CARTAJENA, I., CARRASCO, C., LÓPEZ M., P., DE SOUZA, P., RIVERA, F. \& SANTANDER, B. D., 2017a - Presencia de un centro ceremonial formativo en la Circumpuna de Atacama. Chungara, 49 (1): 3-33.

NúÑEZ, L., CARTAJENA, I., CARRASCO, C., LÓPEZ M., P., DE SOUZA, P., RIVERA, F., SANTANDER, B. \& LOYOLA, R., 2017b - The temple of Tulán: Early formative ceremonial architecture in the Atacama Desert. Antiquity, 91 (358): 901-915.

NÚÑEZ A., L., CARTAJENA, I., CARRASCO, C., LÓPEZ M., P., RIVERA, F., DE SOUZA, P., SANTANDER, B. \& LOYOLA, R., 2016 - Nuevas Excavaciones en Tulán-54: Revelando la Arquitectura Ceremonial Durante el Formativo Temprano de la Puna de Atacama. Revista Chilena de Antropología, 34 (2do semestre): 65-79.

NúÑEZ, L., CARTAJENA, I., DE SOUZA, P. \& CARRASCO, C., 2009a - Temprana arquitectura ceremonial en la Puna de Atacama (Norte de Chile). In: Arqueología del área centro sur andino (M. Ziolkowski, J. Jennings, L. A. Belan Franco \& A. Drusini, eds.): 305-335; Varsovia: Warsaw University Press.

NÙÑEZ ATENCIO, L., DE SOUZA HERREROS, P. F., CARTAJENA FASTING, M. I. \& CARRASCO, C., 2007 - Quebrada Tulan: Evidencias de interacción circumpuneña durante el Formativo Temprano en el sureste de la cuenca de Atacama. In: Producción y circulación prehispánicas de bienes en el sur andino (A. Nielsen, C. 
Rivolta, V. Seldes, M. Vásquez \& P. Mercolli, comps.): 287-304; Córdoba: Colección Historia Social Precolombina, Editorial Brujas.

NÚÑ̃EZ, L., MCROSTIE, V. \& CARTAJENA, I., 2009b - Consideraciones sobre la recolección vegetal y la horticultura durante el Formativo Temparano en el sureste de la cuenca de Atacama. Darwiniana, 47 (1): 56-75.

NÚÑEZ, L. \& SANTORO, C. M., 2011 - El tránsito arcaico-formativo en la Circumpuna y valles occidentales del centro sur andino: Hacia los cambios "neolíticos". Chungara, 43: 487-530.

NúÑEZ, M., 2015 - Sociedad, naturaleza y territorialidad en el desierto y puna de Atacama. Siglos XX al XXI. Tesis para optar al grado de Doctora en Antropología; San Pedro de Atacama: Alianza Universidad Católica del Norte - Universidad de Tarapacá.

ONUKI, Y., 1993 - Las Actividades Ceremoniales Tempranas en la Cuenca del Alto Huallaga y Algunos Problemas Generales. In: El mundo ceremonial andino (L. Millones \& Y. Onuki, eds.): 69-96; Osaka: National Museum of Ethnology. Senri Ethnological Studies 37.

ONUKI, Y., 1999 - El Período arcaico en Huánuco y el concepto del Arcaico. Boletín de Arqueología PUCP, 3: 325-333.

PLANELLA, M. T., 2017 - Informe sobre muestras de flotación recuperadas de los nichos del templete Tulán. Manuscrito no publicado.

QUILTER, J., 2014 - The Ancient Central Andes, xv + 336 pp.; Abingdon, Oxon, Nueva York: Routlege. Routlege World Archaeology.

POSNANSKY, A., 1938 - Antropología y sociología de las razas interandinas y de las regiones adyacentes, 150 pp.; La Paz: Instituto Tiwanaku de Antropología, Etnografía y Prehistoria, Renacimiento.

RASNAKE, R., 1989 - Autoridad y poder en los Andes: los Kuraqkuna de Yura, 282 pp.; La Paz: Hisbol.

RÖSING, I., 1994 - La Deuda de ofrenda: Un concepto central de la religión andina. Revista Andina, 12 (1): 191-216.

SCANU, M., 1987 - Santuarios de Altura en los Andes. Revista del Museo Nacional, 48: 213-249.

SCHIFFER, M., 1987 - Formation processes of the archaeological record, 428 pp.; Alburquerque: University of New Mexico Press.

SCHIFFER, M., 1991 - Los procesos de formación del registro arqueológico. Boletín de Antropología Americana, 23: 39-45.

SHADY, R., 2001 - Caral y Supe y la costa norcentral del Perú: La cuna de la civilización y formación del estado prístino. In: Historia de la cultura peruana, Tomo I (J. G. Lohmann, ed.): 45-88; Lima: Fondo Editorial del Congreso del Perú.

SINCLAIRE, C., URIBE, M., AYALA, P. \& GONZÁLEZ, S., 1997 - La alfarería del periodo Formativo en la región del Loa superior: Sistematización y tipología. In: Contribución Arqueológica, 5: 285-314.

STANDEN, V., KUSMINSKY, S. \& NÚÑEZ, L., Ms - Informe Bioarqueológico. Proyecto FONDECYT 1130917. Manuscrito no publicado.

STOBART, H., 2002 - Sensational Sacrifices: Feasting the Senses in the Bolivian Andes. In: Music, Sensation and Sensuality (L. P. Austern, ed.): 97-120; Nueva York: Routledge.

TANTALEÁN, H., 2006 - Regresar para construir: prácticas funerarias e ideología(s) durante la ocupación inka en Cutimbo, Puno - Perú. Chungara, 38 (1): 129-143.

TARRAGÓ, M., 1989 - Contribución al conocimiento arqueológico de las poblaciones de los oasis de San Pedro de Atacama en relación con los otros pueblos puneños, 
Nichos, cámaras y ceremonias en el templete Tulán-54 (Circumpuna de Atacama, Chile)

en especial al sector septentrional del valle Calchaquí; Rosario: Tesis Doctoral Universidad Nacional de Rosario.

TOMOEDA, H., 1993 - Los ritos contemporáneos de camélidos y la ceremonia de la citua. In: El mundo ceremonial andino (L. Millones \& Y. Onuki, eds.): 289-306; Osaka: National Museum of Ethnology. Senri Ethnological Studies 37.

TOMOEDA, H., 1996 - The concept of vital energy among Andean pastoralists. In: Redefining Nature, Ecology, Culture and Domestication (R. Ellen \& K. Fukui, eds.): 186-212; Oxford: Berg.

WALTER, D., 2002 - L'alpiniste, le paysan et le Parc National du Huascarán; La domestication de la nature sauvage dans les Andes péruviennes; París: Université de Paris III. Tesis doctoral inédita. 